\title{
NARRATIVAS DE PROFESSORAS DE CRECHE: CONCEPÇÕES TEÓRICAS E PRÁTICAS
}

\author{
Izabel Carvalho da Silva, Gilza Maria Zauhy Garms
}

Universidade Estadual Paulista - FCT/UNESP. Presidente Prudente - SP. E-mail: belinhafrench@hotmail.com. $\mathrm{PIBIC/CNPq}$.

\section{RESUMO}

Este trabalho procura apresentar as concepções teóricas e práticas que fundamentam a proposta pedagógica do cotidiano de uma instituição de educação infantil. A coleta de dados foi por meio da narrativa (relatos), observação do cotidiano das instituições acompanhada de registros sobre as práticas educativas e aplicação de um questionário para conhecer o perfil das professoras. Através dos relatos destacamos o que as profissionais de creche compreendem sobre a infância, o desenvolvimento Infantil e a educação de crianças. Dentre os resultados, notamos que as professoras consideram ser imprescindível que a proposta pedagógica na creche seja flexível e atenda as necessidades das crianças. Assim, ao buscar a formação Profissional e a ação do profissional de educação infantil pretendemos promover a melhoria na realidade das instituições infantis e possibilitar a construção de um currículo para a criança de 0 a 3 anos de idade.

Palavras-Chave: Narrativa; Currículo; Proposta Pedagógica; Educação Infantil; Creche.

\section{NARRATIVE OF NURSERY OF TEACHING: CONCEPTIONS THEORY AND PRACTICES}

\begin{abstract}
The research work aims at present the teachers' theoretical conceptions and practices, which found the pedagogical proposal, in the routine of a child education institution. Data collection was through narrative (stories), observation of everyday accompanied by records on educational practices and institutions of a questionnaire to know the profile of the teachers. Through the narrative descriptions, we realized what the teachers understand childhood, child development and education of children. Among the results, we note that the teachers consider it essential that the educational proposal in daycare is flexible and meets the needs of children. Thus, to seek professional training and action of early childhood education professional intend to encourage improvements in the reality of children's institutions, and enable the construction of a curriculum for children 0-3 years old.
\end{abstract}

Keywords: Narrative; Curriculum; Pedagogical Proposal; Child Education; Nursery. 


\section{INTRODUÇÃO}

Creches e pré-escolas são espaços cujos olhares se voltam recentemente no contexto educacional brasileiro. Essa atenção voltada para a infância cumpriu o direito social de crianças frequentarem creches e pré-escolas. Foi a partir da consolidação da Constituição Federal de 1988 que as instituições de Educação Infantil passaram a integrar a educação básica no país.

A obrigatoriedade foi conquista recente vigorada pela Lei $n=12.796$, de 2013 que firmou a Educação a partir dos 4 anos de idade, porém ainda não é obrigatório para as crianças pequenas. $E$ mesmo com essa conquista recente, o desafio passou a ser a constituição do modo como se percebe a criança, quais ações serão feitas diante dessa concepção e principalmente dos professores refletirem sobre seus papéis, de modo a firmar uma concepção, seus saberes e identidades.

Em cumprimento do disposto na Constituição Federal, a LDB 9394/96 insere a criança de 0 a $5^{1}$ anos no contexto da Educação Básica, como primeira etapa deste nível de ensino. Para essa etapa o Estado deve garantir a educação e definir políticas públicas para a infância.

Apesar de ter sido promulgado o direito a educação de crianças a partir de seu nascimento, infelizmente, ainda hoje, deparamos com concepções de educação nas creches cujo caráter está estritamente ligado a uma educação assistencialista no atendimento a crianças de 0 a 3 anos com iniciativas voltadas, prioritariamente, à higiene, saúde e nutrição no âmbito da assistência, do cuidar compreendido como uma ação beneficente aos menos favorecidos economicamente.

Para mudar essa situação, em direção a uma ação com intencionalidade educativa para a primeira infância, defendemos a necessidade de elaborar um currículo para a Educação Infantil e isso se deve ao fato de a criança "ser um sujeito de direitos a serem garantidos, incluindo o direito desde o nascimento a uma educação de qualidade no lar e em instituições escolares" (OLIVEIRA, 2010, p.3).

É válido destacar que não basta às políticas oferecerem tal atendimento, é preciso que se avance mais através da "formação do profissional, para que este, através de um currículo e da proposta pedagógica, faça valer o direito social e humano das crianças de serem educadas e cuidadas e, além disso, viverem plenamente a infância" (GARMS; GUIMARÃES, 2013, p. 32).

Oliveira (2010) referindo-se ao Currículo diz que é um aspecto que gera muitas discussões, no momento em que é entendido na educação infantil como uma preparação aos anos iniciais do Ensino Fundamental. Para ela, esse conceito é percebido como estruturação e organização das instituições infantis, que nos últimos vinte anos é concebido como formas de organização do

\footnotetext{
${ }^{1}$ A etapa da Educação Infantil foi alterada de 0 a 5 anos pela Lei no 12.796, de 2013.
} 
cotidiano das unidades de educação infantil, cujo fim está na promoção do desenvolvimento das crianças e foge da ideia de conteúdos de disciplinas fragmentadas.

Nas Instituições de Educação Infantil a relevância social na construção de um currículo visa organizar os diversos aspectos das unidades de educação infantil como "os tempos de realização das atividades, os materiais disponíveis e, em especial as maneiras do professor exercer seu papel” (Idem, 2010, p.5) enquanto espaços de vivência, aprendizagem e desenvolvimento.

Para a autora a importância do currículo aparece nas creches e pré-escolas como meio de concretizar situações cotidianas favoráveis à convivência agradável entre crianças, crianças e adultos, a brincadeira em grupo, o expressar-se, o comunicar-se, bem como, criar e reconhecer novas linguagens. É relevante considerar a comunidade em que a criança está inserida e sua família ao apreciar o planejamento do currículo nas instituições de educação infantil e em sua elaboração deve haver a participação coletiva dos professores, da comunidade e das crianças.

Kramer (1994 apud BRASIL, 1996) defende que não há diferença conceitual entre proposta pedagógica e currículo. A autora compreende currículo de forma ampla, dinâmica e flexível, que é a maneira como se tem concebido uma proposta pedagógica. Ela afirma que toda proposta pedagógica tem uma história que necessita ser contada e que toda proposta contém uma aposta e, portanto nasce da realidade que questiona e é também busca de uma resposta. Desde modo, acredita que é um caminho a se construir.

Quanto ao currículo as Diretrizes Curriculares Nacionais da Educação Infantil (BRASIL, 2009) apontam que as práticas planejadas devem considerar a integralidade e indivisibilidade das dimensões expressivo-motora, afetiva, cognitiva, lingüística, ética, estética e sociocultural das crianças, assim como indicam que as experiências de aprendizagens promovidas junto às crianças necessitam efetivar-se por meio de modalidades que assegurem as metas educacionais de seu projeto pedagógico.

Ainda sobre essa relevância de se construir um currículo para Educação Infantil especificadamente para crianças de 0 a 3 anos, outro aspecto nos faz ver sua importância, como reconhecer que a aprendizagem infantil se dá através das habilidades que a criança constrói ao conquistar sua independência, portanto, é capaz de participar e ser crítica com relação ao mundo em que vive, tudo isso adquirido por meio das relações que ela estabelece.

Porém, Kuhlmann (2001) destaca que as propostas de programação para a educação infantil no país estariam desconsiderando o universo cultural da criança e apenas focando no desenvolvimento intelectual, organizado em áreas fragmentadas com destaque para a 
alfabetização, desvalorizando o jogo e o brinquedo como atividades essenciais para a criança e deixando de explicitar articulações entre o cuidado e a educação.

Com a mudança do direito à educação para as crianças as experiências promovidas pelo professor no cotidiano das instituições de Educação Infantil devem "possibilitar o encontro de explicações pela criança sobre o que ocorre à sua volta e consigo mesma enquanto desenvolvem formas de sentir, pensar e solucionar problemas" (OLIVEIRA, 2010, p.6).

Na defesa de se elaborar um currículo para a Creche, a tarefa dos professores segundo Barbosa (2010, p.8) é "criar um ambiente onde as crianças possam viver, brincar e serem acompanhadas em suas aprendizagens individuais e também em pequenos grupos, lembrando que os ambientes precisam ser coerentes com as necessidades das crianças, proporcionando situações de desafios, mas também oferecendo segurança".

Para isso é que conforme a Lei no9394/96 art.29 a educação infantil na primeira etapa da Educação Básica tem a finalidade de promover o desenvolvimento integral da criança de zero a cinco anos de idade em seus aspectos físicos, afetivo, intelectual, linguístico e social, complementando a ação da família.

Deste modo, Garms e Guimarães (2011) afirmam que há, portanto, um grande desafio oferecer o acesso à educação desde os primeiros meses de vida a todas as crianças e superar o desafio da qualidade do atendimento infantil. E se falando de qualidade esta está vinculada ao atendimento da criança na instituição de educação infantil, como também ao currículo que orienta (ou deveria orientar) tal atendimento.

Nesse contexto o objetivo da pesquisa é apresentar as concepções teóricas e práticas dos professores que fundamentam as propostas pedagógicas, as diretrizes e os princípios que a estabelecem, o processo como foram construídas e como informam a prática no cotidiano dos estabelecimentos de educação infantil.

\section{METODOLOGIA}

A figura do professor é imprescindível nas Instituições de Educação Infantil, reconhecido como um dos responsáveis pela educação de qualidade requerida, para tanto, usamos de suas narrativas como meio para buscar o "olhar", a subjetividade de seu trabalho e recolher resultados face aos objetivos expostos.

Nesse sentido nos apropriamos do conceito de André (2001) ao apresentar a pesquisa qualitativa como aspecto de relevância cientifica e social, o que significa estar inserida num 
quadro teórico em que se evidencie sua contribuição ao conhecimento já disponível e a opção por temas pertinentes na prática social.

A pesquisa de cunho qualitativo, de acordo com o que apresentam Bogdan e Biklen (1994, p.13), "envolve a obtenção de dados descritivos, alcançados no contato direto do pesquisador com a situação estudada, enfatiza mais o processo do que o produto e se preocupa em retratar a perspectiva dos participantes".

As narrativas, tipo de pesquisa em educação, tem sido instrumento de formação e investigação no contexto educacional, pois no momento em que os professores narram suas experiências "acabam compreendendo a si próprios e aos outros, caracterizando-se como uma estratégia emancipadora de tomada de consciência e formação" (COSTA; SILVA, 2010, p.2).

A importância de usar as narrativas como metodologia na pesquisa em educação constitui para as autoras "acesso e reconstrução das vivências experienciadas objetivando contribuir para a formação dos professores, através da escuta da voz do professor, a história narrada constitui elemento primordial nessa construção" (Idem, 2010, p.9).

No campo empírico, foram aplicados questionários junto às professoras envolvidas na pesquisa da Creche Pingo de Ouro $^{2}$ da cidade de Regente Feijó. A leitura dos dados permitiu tabular o perfil, este identificado por meio de vinte itens. Questões abertas também foram incorporadas ao questionário.

Os dados foram obtidos junto a cinco professoras da instituição municipal de Educação Infantil, especificadamente às que atendem às crianças de 0 a 3 anos, sendo duas professoras do Berçário I (0-2 anos) e três professoras do Maternal I (2-3 anos) que versaram sobre os seguintes aspectos: o que fazem e como fazem os professores; quais recursos intelectuais e materiais utilizam; como relatam o que fazem.

Usamos de um gravador para colher o relato oral individual em que o profissional abordou um dia de trabalho na educação infantil, desde quando chegou à instituição até o momento em que vai embora. Fizemos a observação do cotidiano da instituição acompanhada de registros sobre as práticas educativas.

Os profissionais envolvidos na pesquisa assinaram um Termo de Consentimento Livre Esclarecido, bem como, tivemos a autorização da Diretora Municipal de Educação.

Para o aprofundamento de estudos foram lidos documentos oficiais como a Política Nacional de Educação Infantil: pelo direito das crianças de zero a seis anos à Educação (2006); a Revisão das Diretrizes Curriculares Nacionais para a Educação Infantil (2009). A fundamentação

\footnotetext{
${ }^{2}$ O Nome da escola foi preservado.
} 
teórica sobre as narrativas (relatos) está pautada especialmente nas obras de Galvão (2005), Reis (2008) e Rabelo (2011). Também foram lidos referenciais teóricos que versam sobre o Currículo/Proposta Pedagógica na Educação Infantil.

\section{RESULTADOS}

$\mathrm{Na}$ análise das narrativas se considerou os seguintes episódios: Chegada das crianças, Alimentação, Estimulação do Desenvolvimento das crianças, Hora do Sono e Retorno ao Lar. Excertos que permitiram inferir que as ações das professoras estão fundamentadas em documentos legais sobre a Educação Infantil.

A rigor, foi possível constatar que as professoras compreendem a infância como momento singular em cujo processo a criança é considerada como sujeito social e histórico, dotado de identidade própria com particularidades singulares quando o modo de ser e de pensar, portanto, diferente do adulto.

O desenvolvimento infantil para elas ocorre a partir das interações das crianças com seus pares, com o ambiente e recursos por este disponibilizado e, sobretudo na interação com os adultos. Nesse processo o objetivo é a formação integral da criança, nos aspectos cognitivos, emocionais, afetivos e físicos.

Neste contexto, a Educação Infantil é entendida como espaço de promoção do bem estar da criança e espaço de estimulações por meio de ações que envolvem o cuidar e o educar, permeados pela brincadeira que permite à criança interpretar a realidade tornando-se protagonista de suas ações.

Confirmar os pressupostos teóricos dos professores como fizemos neste trabalho é uma forma de considerar o que a metodologia da narrativa considera como potencialidades, as quais foram explicitas por Galvão (2005, p. 327), a saber: “[...] como processo de investigação em educação, como processo de reflexão pedagógica e como processo de formação".

\section{DISCUSSÃO}

Uma das figuras essenciais para desenvolver uma Proposta Pedagógica na creche é o Professor, para tanto, é preciso que os Cursos de Formação de Professores, no bojo da licenciatura em Pedagogia, tenham em suas grades curriculares disciplinas com foco na educação Infantil creche e pré-escola- e não só nas séries iniciais do Ensino Fundamental. Precisa fazer parte da grade curricular disciplinas sobre a história na educação Infantil no país, legislação voltada para a 
área, estágios devidamente supervisionados em que há a associação teoria e prática para o professor se inteirar do seu futuro campo de atuação profissional.

Para uma ação planejada com crianças é preciso também que outros aspectos institucionais sejam considerados, tais como, condições de trabalho do professor, sua qualificação profissional, programas de capacitação em serviço, o número de crianças por sala, os recursos humanos, materiais e financeiros disponíveis. É relevante também a relação dialógica entre a escola e a comunidade, professores e famílias, professores e professores, professores e crianças e, indiscutivelmente, interações de crianças com seus pares, valorizando o diálogo e trocas entre os envolvidos na educação das crianças (MACHADO, 2000).

Contudo é preciso atentar para a formação de professores capazes de "integrarem os sistemas educacionais e, simultaneamente, atuarem nas modalidades de ensino sustentados em aportes teóricos fundamentados de modo consistente nas necessidades e características do desenvolvimento das crianças" (Idem, 2000, p.191).

\section{CONCLUSÃO}

Com esta pesquisa tivemos a pretensão de desmistificar a visão de que as instituições de educação infantil não precisam de um planejamento, ao contrário, necessitam sim de um currículo/proposta pedagógica que organize os diversos aspectos das unidades de educação infantil como o espaço, tempo, os materiais e, de modo geral, as ações do professor que necessitam de um aporte teórico que as subsidie. Nesse sentido, os resultados apareceram em razão da existência de um currículo/proposta que as professoras junto ao município pesquisado vêm construindo ao longo de tempo.

Nesse trabalho, procuramos demonstrar que não basta às políticas públicas oferecerem o atendimento em creches e pré-escolas, é preciso que se avance mais através da "formação do profissional, para que este, através de um currículo e da proposta pedagógica, faça valer o direito social e humano das crianças de serem educadas e cuidadas e, além disso, viverem plenamente a infância" (GARMS; GUIMARÃES, 2013, p. 32).

Um dos elementos mais importante para a educação de qualidade é o professor. Sem o docente de qualidade não há uma educação de qualidade, e para este, enquanto agente de transformação da realidade social é preciso pensar na sua formação, motivação, condições de trabalho e formação continuada que implicará uma melhoria na prática.

Garms; Lopes e Marin (2012, p. 13-14) admitem que o fato do profissional narrar sobre o seu exercício é "fundamental por 'permitir olhar' para a prática e dialogar com a teoria e vice- 
versa com o objetivo de detectar e desconstruir, se for o caso, eventuais crenças e concepções que não respeitem à criança como sujeito de direitos". Reflexões realizadas ao longo do tempo poderão provocar melhorias, aperfeiçoando o fazer do professor.

\section{REFERÊNCIAS}

ANDRÉ, M. E. D. A. de. Pesquisa em educação: buscando rigor e qualidade. Caderno Pesquisa. São Paulo, n..113, jul. 2001.

BARBOSA, Maria C. S. As especificidades da ação pedagógica com bebês. Porto Alegre: Artmed, 2010.

BOGDAN, R. C.; BIKLEN, S. K.; Investigação qualitativa em educação: uma introdução à teoria e aos métodos. Porto: Porto Ed. 1994.

BUJES. M. I. E. Educação infantil: pra que te quero. Rio de Janeiro: DP\&A, 2001.

BRASIL. Ministério da Educação e do Desporto. Referencial Curricular Nacional para a Educação Infantil. Brasília: MEC/ SEF, 1998.

. Lei de Diretrizes e Bases da Educação Nacional. Lei n. 9394 promulgada em 20 de dezembro de 1996. São Paulo: Roma Victor ed., 2007.

Resolução CEB n. 5 de 17 de Dezembro de 2009. Fixa as Diretrizes Curriculares Nacionais para a Educação Infantil.

COSTA, M. L.; SILVA, M. R. F. V. Narrativas e pesquisa em educação: possibilidades formativas e investigativas. In: Encontro de Pesquisa em Educação da UFPI, 6, 2010, p. 1-14.

GARMS, G.M.Z; GUIMARÃES, C. M. A Legislação, As Políticas Nacionais De Atendimento Na Instituição De Educação Infantil No Brasil E O Desafio De Cuidar E Educar A Criança De 0 A 5/6 Anos. Cadernos de Educação da Infancia da Associação de Profissionais de Educação da Infancia. Portugal. e. dez/2011. p. 1-26.

GARMS, G.M.Z; GUIMARÃES, C. M. Currículo para a educação e o cuidado da criança de 0 a 5 anos? Rev. educ. PUC-Camp., Campinas, 18(1):19-35, jan./abr., 2013.

GARMS, G.M.Z; LOPES, T. C.; MARIN, F. A. D. G. Profissionalização na educação infantil: as práticas educativas como objeto de reflexão, 2012.

GALVÃO, C. Narrativas em Educação. In: Ciência \& Educação, v. 11, n. 2, p. 327-345, 2005.

KUHLMANN JR., M. Infância e educação infantil: uma abordagem histórica. Porto Alegre: Mediação, 2001.

MACHADO, M. L. A., Desafios Iminentes para projetos de Formação de Profissionais para a Educação Infantil. Cadernos de Pesquisa, no 110, p. 191-202, julho/ 2000. 
MELLO, A.M. A Construção da identidade na infância. IN: MELLO,A.M...[et al.]. 0 dia a dia das creches e pré-escolas: crônicas brasileiras. Porto Alegre: Artmed, 2010.

OLIVEIRA. Z. M. R. O Currículo na educação infantil: O que propõem as novas diretrizes nacionais?. São Paulo: Cortez, 2010. 